\title{
Calculating the accuracy of strain observations of high-rise buildings and structures using electronic total stations
}

\author{
Vladimir Simonjan ${ }^{1, *}$ and Svetlana Shendyapina ${ }^{1}$ \\ ${ }^{1}$ Moscow State University of Civil Engineering, 26, Yaroslavskoye Shosse, 109377, Moscow, Russia
}

\begin{abstract}
The most important task related to the life activity of people and their safety is the monitoring of buildings and structures. The purpose of monitoring is to identify the degree of physical condition of building structures, the impact of various factors on their physical condition and design performance. Geodetic observations of horizontal and vertical displacements of buildings and structures are most common. They are the most important part of geodetic monitoring. Underestimating the importance of monitoring or not doing so in order to save money leads to tragic consequences. Therefore, the article deals with the accuracy of observations of horizontal and vertical displacements of high-rise buildings and structures using electronic total stations.
\end{abstract}

\section{Introduction}

The main purpose of the observations is to determine the values of deformation to assess the stability of the structure and take timely preventive measures to ensure the normal operation of the structure.

When performing geodetic works on monitoring of buildings and structures, the geodetic service usually develops a special design for the production of geodetic works (DPGW), which according to [8, item 3.7] must necessarily include:

- selection of observation methods;

- a scheme for building a geodesic base indicating the types of geodesic signs and their location;

- calculation of the required and expected accuracy of the justification creation and the resulting measurement results;

- list of devices and tools;

- processing and analysis of measurement results.

\section{Materials and methods}

For the study of deformations in the characteristic points of a building, usually at ground floor reinforce sediment benchmarks or marks in the same horizon, which are subjected to

*Corresponding author: simonyan.vladimir55@gmail.com 
displacement together with the object, set initial position and time reference and to determine the changes of their spatial position for a selected period of time, i.e., receive the corresponding characteristics of the movement of the object in whole and its parts.

To determine the absolute precipitation $\mathrm{S}$ of marks fixed on the building, their elevation $\mathrm{H}$ is periodically determined relative to the initial benchmarks located away from the building and taken as fixed.

The main method for measuring vertical movements is precise geometric leveling.

The precipitation of the marks at the current moment since the beginning of observations is determined by the formula:

$$
\mathrm{S}=\mathrm{H}_{\text {current. }}-\mathrm{H}_{\text {initial }} \text {. }
$$

Where $\mathrm{H}_{\text {current. }}, \mathrm{H}_{\text {initial. }}$ - - the height of the stamp at the current and initial time points, respectively.

Similarly, the precipitation for the time between the previous and subsequent observation cycles is calculated. The horizontal offset $\mathrm{q}$ of a single point in a building is determined by the difference in its coordinates at the current and initial time points ( $\mathrm{X}_{\text {current., }}$ $\mathrm{Y}_{\text {current. }}$ and $\mathrm{X}_{\text {initial. }}$, $\mathrm{Y}_{\text {initial. }}$ ). Offsets along the $\mathrm{X}$ and $\mathrm{Y}$ axes $\left(\mathrm{q}_{\mathrm{X}}\right.$ and $\left.\mathrm{q}_{\mathrm{Y}}\right)$ are calculated using the following formulas:

$$
\begin{aligned}
& q_{X}=X_{\text {current. }}-X_{\text {initial. }}, \\
& q_{Y}=Y_{\text {current. }}-Y_{\text {initial. }} .
\end{aligned}
$$

Similarly, the offsets between the previous and subsequent observation cycles are calculated.

According to the results of observations of deformations of buildings form a technical conclusion on its condition and forecast of development of the identified strains, recommendations were developed for appropriate measures, warning of the negative consequences of critical strain.

The correct choice of accuracy and frequency of observations depends on the methods and means of measurement, the cost of their production and the reliability of the results obtained.

The accuracy and frequency of measurements are specified in the technical task for the production of works or in regulatory documents.

Requirements for the accuracy of determining the deformation characteristics (accuracy class) of the surrounding existing building are set on the basis of table 1 [7]:

Table 1. Defining the measurement accuracy class.

\begin{tabular}{|c|l|c|c|}
\hline $\begin{array}{c}\text { Class of accuracy } \\
\text { of determination } \\
\text { of deformation } \\
\text { characteristics }\end{array}$ & \multicolumn{1}{|c|}{ Types of buildings and structures } & \multicolumn{2}{|c|}{$\begin{array}{c}\text { The standard error of } \\
\text { determination of deformation } \\
\text { characteristics (mm) }\end{array}$} \\
\cline { 2 - 4 } & $\begin{array}{c}\text { Vertical } \\
\text { Horizontal }\end{array}$ \\
\hline I & $\begin{array}{l}\text { - Unique; } \\
\text { - In operation for more than 50 years; } \\
\text { - Built on rock and semi-rock soils }\end{array}$ & 1 & 2 \\
\hline II & $\begin{array}{l}\text { Built on sandy, clay and other } \\
\text { compressible soils }\end{array}$ & 2 & 5 \\
\hline III & $\begin{array}{l}\text { Built on bulk, subsidence, blocked and } \\
\text { other highly compressible soils }\end{array}$ & 5 & 10 \\
\hline IV & Earthwork & 10 & 15 \\
\hline
\end{tabular}


So, for the second class of accuracy in determining the deformation characteristics of buildings and structures built on sandy, clay and other compressible soils, the standard errors are as follows: for vertical displacements $-2 \mathrm{~mm}$, for horizontal $-5 \mathrm{~mm}$. For the third class of accuracy for buildings and structures built on bulk, subsidence, blocked and other highly compressible soils, these errors are 5 and $10 \mathrm{~mm}$, respectively. At the same time, it is recommended to observe precipitation using the geometric leveling method.

For buildings and structures under construction, the accuracy class for determining deformation characteristics must be set depending on the expected values of deformations of the base of objects under construction. The accuracy class or expected values of deformations are specified in the project documentation. A preliminary calculation of the measurement of the sediment of the foundations of structures is given in table 2, where the conditional division of soils in the base into sandy and clay depending on the calculated amount of sediment is given [9]:

Table 2. Standard error of sediment measurements for buildings under construction for one cycle.

\begin{tabular}{|c|c|c|}
\hline \multirow{2}{*}{$\begin{array}{c}\text { Estimated amount } \\
\text { of sediment, } \mathbf{~ m m}\end{array}$} & \multicolumn{2}{|c|}{ Construction period } \\
\cline { 2 - 3 } & Sandy & Clay \\
\hline 50 & 1 & 1 \\
\hline 100 & 2 & 1 \\
\hline 150 & 3 & 2 \\
\hline 200 & 4 & 3 \\
\hline 250 & 5 & 3 \\
\hline 300 & 6 & 4 \\
\hline
\end{tabular}

Depending on the expected sediment, geometric leveling methods of class I, II, or III are used.

\section{Results}

Sometimes it is necessary to conduct geodetic monitoring in an emergency. For example, on November 11, 2013, in the village of Zagorskiye Daly, Sergiev Posad district of the Moscow region, an explosion of household gas occurred in the third entrance of house No 3. The center of the explosion was one of the apartments on the eighth floor of four entrances of nine floors panel house. As a result, some of the apartments on the eighth and ninth floors were completely destroyed, and from the entrances (figure 1) the destruction was much more severe than on the opposite side (figure 2).

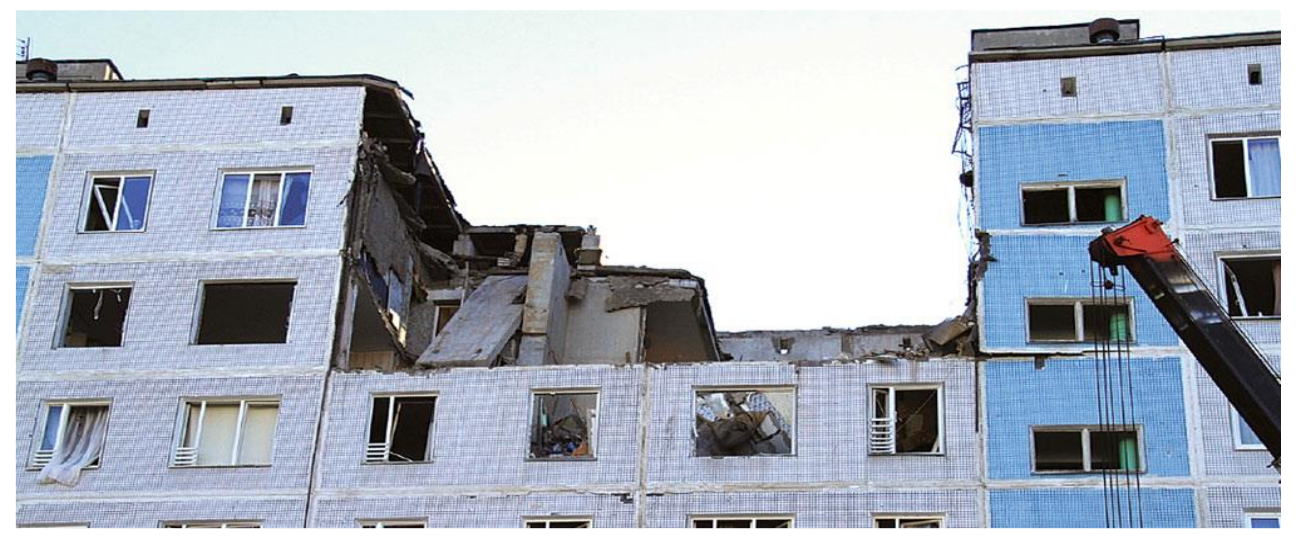

Fig. 1. Destroyed part of the building from the entrances. 


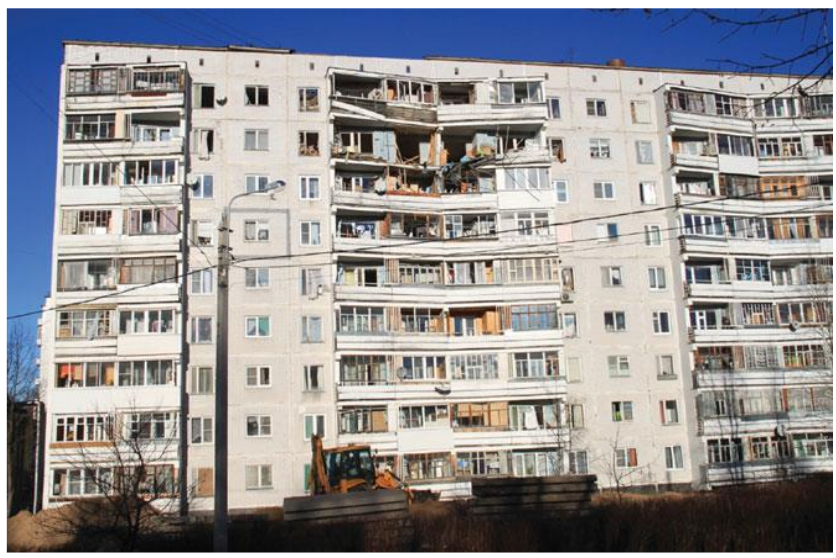

Fig. 2. General view of the affected building from the side opposite the entrances.

To determine the actual deformations of this building, it is necessary, first, to identify deviations of the surviving structures from the design position (which could occur both during the explosion and during construction) and, secondly, to follow the change in the geometry of the house during the dismantling of its destroyed parts and conducting repair and restoration work. Therefore, it makes no sense to fix the deformation marks at the ground floor level. They should be fixed directly on the destroyed part of the structure. The quality, completeness and validity of the obtained data on the deformations largely depend on the location and quantity of marks, which depends on the purpose of the work, types of deformations, building structure and its separate elements, etc. From this point of view optimal is the location of deformation marks on the transverse axis 4 and partially the 3rd entrances on each floor. This will allow you to identify deviations of the walls from the vertical and make a conclusion about the possibility of using the 4th entrance or the need for its demolition. But in the latter case, it will not be possible to apply the geometric leveling method because of the large angles of inclination. Then the question arises about the use of electronic total stations and what the accuracy of measurements should be $[1,3]$.

The widespread use of electronic total stations in engineering and geodesic works, which provide speed, automation and sufficient accuracy of measurements, expands the possibilities of trigonometric leveling. However, when working with a total station, you need a reflector fixed to the surface of the object. Such a reflector can serve as a special category film reflector. In addition, the use of electronic total stations with measurement errors of horizontal and zenith angles $\mathrm{m}_{\beta}=\mathrm{m}_{\mathrm{z}}=1-3^{\prime \prime}$ and distances $\mathrm{m}_{\mathrm{s}=1-4 \mathrm{~mm}}$ and less, contributes to their use in the control of deformations.

\section{Discussion}

We will set the necessary accuracy for measuring deformations when using electronic total stations.

In the coordinate method, the deformation point is determined relative to the source point in a polar way. The coordinates of the $\mathrm{i}$-th deformation mark $\mathrm{X}_{\mathrm{i}}$ and $\mathrm{Y}_{\mathrm{i}}$ will be based on the formulas:

$$
\begin{aligned}
& X_{i}=X_{p}+\Delta X_{p-i}=X_{p}+S_{p-i} \quad \cos \alpha_{P-i} \\
& Y_{i}=Y_{p}+\Delta Y_{p-i}=Y_{p}+S_{p-i} \quad \sin \alpha_{P-i}
\end{aligned}
$$


Where $X_{P}, Y_{P}$ - coordinates of the station, determined by the method of reverse serif from the reference points $\Delta \mathrm{X}_{\mathrm{P}-\mathrm{i}}, \Delta \mathrm{Y}_{\mathrm{P}-\mathrm{i}}$-increments of coordinates along the line "P $-\mathrm{i}$ " (between the station and the deformation mark); $\mathrm{S}_{\mathrm{P}-\mathrm{i}}-$ the length of the horizontal line "P i"; $\alpha_{\mathrm{P}-\mathrm{i}}$-the directional angle of the line "P -i".

Accuracy of determining these coordinates:

$$
\begin{aligned}
& m_{X_{i}}=\sqrt{m_{X_{P}}^{2}+\cos ^{2} \alpha_{P-i} \cdot m_{S_{P-i}}^{2}+S_{P-i}^{2} \sin ^{2} \alpha_{P-i} \frac{m_{\alpha_{P}-i}^{2}}{\rho^{2}}} ; \\
& m_{Y_{i}}=\sqrt{m_{Y_{P}}^{2}+\cos ^{2} \alpha_{P-i} \cdot m_{S_{P-i}}^{2}+S_{P-i}^{2} \sin ^{2} \alpha_{P-i} \frac{m_{\alpha_{P}-i}^{2}}{\rho^{2}}}
\end{aligned}
$$

Where $\mathrm{m}_{\mathrm{X}_{\mathrm{P}}}, \mathrm{m}_{\mathrm{Y}_{\mathrm{P}}}$ is the standard error of determination of coordinates of stations obtained by the back sight from the reference points;

$\mathrm{m}_{\mathrm{S}_{\mathrm{P}-\mathrm{i}}}$ - standard error in determining the length of the horizontal line "P -i"; - standard error in determining the directional angle of the line "P -i"; $\rho$ - the number of radians in seconds, equal to 206265".

General standard error in determining of the planned position of the i-th deformation point:

$$
m_{i}=\sqrt{m_{X_{i}}^{2}+m_{Y_{i}}^{2}}=\sqrt{m_{P}^{2}+m_{S_{P-i}}^{2}+S_{P-i}^{2} \frac{m_{\alpha_{P}-i}^{2}}{\rho^{2}}},
$$

Where $m_{P}=\sqrt{m_{X_{P}}^{2}+m_{Y_{P}}^{2}}$ is the standard error of determining the station coordinates obtained by the inverse angular serif.

Since the directional angle $\alpha_{\mathrm{P}-\mathrm{i}}$ is calculated from the measured angle $\beta$, the standard error of the directional angle of the line between the station and the deformation point is characterized by the standard error $\mathrm{m}_{\beta}$ of the measured angle $\beta$ (the angle between the directions to the reference and deformation points), then equation (5) will take the following form [4]:

$$
m_{i}=\sqrt{m_{P}^{2}+m_{S_{P-i}}^{2}+S_{P-i}^{2} \frac{m_{\beta}^{2}}{\rho^{2}}}
$$

Initial condition for calculating the accuracy of angular and linear measurements:

$$
\Delta \mathrm{S} \geq \mathrm{z}_{\mathrm{q}} \mathrm{m}_{\Delta \mathrm{i}}
$$

Where $\Delta \mathrm{S}$ is the tolerance for determining the planned displacement of the deformation points; $\mathrm{m}_{\Delta \mathrm{i}}$ - the standard error of this offset; $\mathrm{z}_{\mathrm{q}}$ - the coefficient depending on the accepted confidence probability $\mathrm{p}$ or on the significance level $\mathrm{q}=(1-\mathrm{p})$ :

\section{Q}

0.1000

0.0500

0.0100

0.0027

0.0001

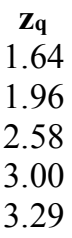

1.64

1.96

2.58

3.00

3.29

From inequality (7) it follows: 


$$
\mathrm{m}_{\Delta \mathrm{i}} \leq \frac{\Delta \mathrm{S}}{\mathrm{z}_{\mathrm{q}}}
$$

Since the displacement of the deformation point is determined by the difference in its coordinates between the observation cycles, the standard error of the planned position of the $i$-th point $m_{i}$ in each of the observation cycles must satisfy the condition:

$$
\mathrm{m}_{\mathrm{i}} \leq \frac{\Delta \mathrm{S}}{\mathrm{z}_{\mathrm{q}} \sqrt{2}}
$$

From formula (6) and condition (9) we get:

$$
\Delta \mathrm{S} \geq \mathrm{z}_{\mathrm{q}} \mathrm{m}_{\mathrm{i}} \sqrt{2} \geq \mathrm{z}_{\mathrm{q}} \sqrt{2} \sqrt{\mathrm{m}_{\mathrm{P}}^{2}+\mathrm{m}_{\mathrm{S}_{\mathrm{P}-\mathrm{i}}}^{2}+\mathrm{S}_{\mathrm{P}-\mathrm{i}}^{2} \frac{\mathrm{m}_{\beta}^{2}}{\rho^{2}}} .
$$

Let's use the principle of equal influence of error sources. So:

$$
\mathrm{m}_{\mathrm{S}_{\mathrm{P}-\mathrm{i}}}=\frac{\mathrm{S}_{\mathrm{P}-\mathrm{i}}}{\rho} \mathrm{m}_{\beta}=\mathrm{m}_{\mathrm{P}}=\mathrm{m} \text {. }
$$

From inequality (10) we get:

$$
\mathrm{m} \leq \frac{\Delta \mathrm{S}}{2,4 \mathrm{z}_{\mathrm{q}}}
$$

Therefore:

$$
\begin{aligned}
& m_{S} \leq \frac{\Delta S}{2,4 z_{q}}=0,21 \Delta S \\
& \mathrm{~m}_{\beta} \leq \frac{\Delta \mathrm{S} \rho}{2,4 \mathrm{z}_{\mathrm{q}} \mathrm{S}}=0,21 \Delta \mathrm{S} \frac{\rho}{\mathrm{S}} .
\end{aligned}
$$

The obtained formulas make it possible to calculate the accuracy of linear and angular measurements to determine the planned position of the deformation points directly in relation to the reference points at a given tolerance on the determination of the target displacement.

For example, for $\Delta \mathrm{S}=5 \mathrm{~mm}$ and $\mathrm{S}=50 \mathrm{~m}$, for the probability $\mathrm{p}=0.95\left(\mathrm{z}_{\mathrm{q}}=1.96\right)$, we get: $\mathrm{m}_{\mathrm{s}} \leq 1,1 \mathrm{Mm} ; \mathrm{m}_{\beta} \leq 4,3^{\prime \prime}$.

Using the principle of equal effects of error sources, for

$$
\mathrm{m}_{\mathrm{P}}=\sqrt{\mathrm{m}_{\mathrm{X}_{\mathrm{P}}}^{2}+\mathrm{m}_{\mathrm{Y}_{\mathrm{P}}}^{2}}
$$

Assume that $\mathrm{m}_{\mathrm{Xp}}=\mathrm{m}_{\mathrm{Yp}}=\mathrm{m}$. Then we get:

$$
\mathrm{m}_{\mathrm{P}}=\mathrm{m} \sqrt{2}
$$

The accuracy of the reverse angular serif $m_{P}$ is affected by the errors of the actual serif and the initial (reference) points. In our constructions, the errors of reference points can be ignored.

The accuracy of determining the coordinates of the station depends on the accuracy of the actual reverse angle serif. The standard error of the inverse angular serif $m_{P}$ can be calculated using the following approximate formula [6]: 


$$
\mathrm{m}_{\mathrm{P}}=\frac{\mathrm{m}_{\beta}}{\left|\rho \sin \left(\gamma_{1}+\gamma_{2}+\omega_{\mathrm{BAC}}\right)\right|} \frac{\mathrm{s}_{\mathrm{AP}}}{\sqrt{\left(\frac{\mathrm{s}_{\mathrm{BP}}}{\mathrm{b}_{\mathrm{AB}}}\right)^{2}+\left(\frac{\mathrm{s}_{\mathrm{CP}}}{\mathrm{b}_{\mathrm{AC}}}\right)^{2}}},
$$

Where $\mathrm{S}_{\mathrm{AP}}, \mathrm{S}_{\mathrm{BP}}, \mathrm{S}_{\mathrm{CP}}$ is the distance from station $\mathrm{P}$ to reference points $\mathrm{A}, \mathrm{B}, \mathrm{C}$, respectively; $b_{A B}, b_{A C}$ is the distance between reference points $A$ and $B, A$ and $C$, respectively; $\omega_{\mathrm{BAC}}$ - the angle between the original sides of the triangle formed by the reference points B, A, C; $\gamma_{1}, \gamma_{2}$-the horizontal angles between the reference points measured at the station.

Under $\mathrm{m}_{\beta}=3^{\prime \prime}, \mathrm{S}_{\mathrm{AP}}=55.4 \mathrm{~m}, \mathrm{~S}_{\mathrm{BP}}=25.8 \mathrm{~m}, \mathrm{~S}_{\mathrm{CP}}=38 \mathrm{~m} 7 \mathrm{~m}, \gamma_{1}=77.2^{\circ}, \gamma_{2}=89.4^{\circ}, \omega_{\mathrm{BAC}}$ $=64.4^{\circ}, \mathrm{b}_{\mathrm{AB}}=60.8 \mathrm{~m}, \mathrm{~b}_{\mathrm{AC}}=60.1 \mathrm{~m}$ we get the formula $(15): \mathrm{m}_{\mathrm{P}}=1.3 \mathrm{~mm}$.

Then, taking into account the formula (14), we get: $\mathrm{m}=\mathrm{m}_{\mathrm{p}} / \sqrt{2}=11 \mathrm{~mm}$, that is, $\mathrm{m}_{\mathrm{Xp}}=$ $\mathrm{m}_{\mathrm{Yp}}=11 \mathrm{~mm}$ and standard errors for determining the coordinates of deformation points at $\alpha$ $=45^{\circ}, \mathrm{m}_{\mathrm{S}}=2 \mathrm{~mm}, \mathrm{~m}_{\mathrm{S}}=50 \mathrm{~m}, \mathrm{~m}_{\beta}=3^{\prime \prime}$ according to the formulas (4): $\mathrm{m}_{\mathrm{Xi}}=2.5 \mathrm{~mm} ; \mathrm{m}_{\mathrm{Yi}}=$ $2.5 \mathrm{~mm}$, and standard error of the horizontal displacements by the formula (2): $\mathrm{m}_{\mathrm{qx}}=$ $\mathrm{mX} \sqrt{ } 2=2.5 \mathrm{~mm} \sqrt{ } 2=3.5 \mathrm{~mm}, \mathrm{~m}_{\mathrm{qr}}=\mathrm{m}_{\mathrm{Y}} \sqrt{ } 2=2.5 \mathrm{~mm} \sqrt{ } 2=3.5 \mathrm{~mm}$.

The obtained values of standard errors of horizontal displacements are in good agreement with table 2 of the manual [7] for the second class of accuracy in determining deformation characteristics for buildings and structures built on sandy, clay and other compressible soils.

The height of the i-th deformation point is calculated using the formula [2]:

$$
\mathrm{H}_{\mathrm{i}}=\mathrm{H}_{\mathrm{P}}+\mathrm{h}_{\mathrm{P}-\mathrm{i}}=\mathrm{H}_{\mathrm{P}}+\mathrm{D}_{\mathrm{P}-\mathrm{i}} \operatorname{cosz}_{\mathrm{P}-\mathrm{i}}
$$

Where $H_{P}$ is the station height $\mathrm{P} ; \mathrm{h}_{\mathrm{P}-\mathrm{i}}$ - is the excess between the station and the deformation point; $\mathrm{D}_{\mathrm{P}-\mathrm{I}}$ is the distance from the station to the deformation mark; $\mathrm{z}_{\mathrm{P}-\mathrm{i}}$ - is the zenith distance between the station and the deformation mark. Accuracy of determining the height of the deformation point:

$$
m_{H_{i}}=\sqrt{m_{H_{P}}^{2}+\cos ^{2} z_{P-i} \cdot m_{D_{P-i}}^{2}+D_{P-i}^{2} \sin ^{2} z_{P-i} \frac{m_{z_{P}-i}^{2}}{\rho^{2}}}
$$

Where $m_{D}$ is the standard error of distance measurement; $m_{z}$ - standard error of measurement of zenith distances.

For leveling, the initial condition for calculating the accuracy of measuring vertical angles by analogy with the condition (7) is presented as follows:

$$
\Delta \mathrm{H} \geq \mathrm{m}_{\Delta \mathrm{HZ}} \mathrm{Z}_{\mathrm{q}}
$$

Where $\Delta \mathrm{H}$ is the tolerance for determining the vertical displacement of the deformation point; $\mathrm{m}_{\Delta \mathrm{H}}$ - is the standard error of this displacement.

Doing the same as when determining the accuracy of horizontal angles, we get a condition for calculating the accuracy of measuring vertical angles:

$$
\Delta \mathrm{H} \geq \mathrm{z}_{\mathrm{q}} \mathrm{m}_{\mathrm{H}} \sqrt{2} \geq \mathrm{z}_{\mathrm{q}} \sqrt{2} \cdot \sqrt{\mathrm{m}_{\mathrm{H}_{\mathrm{P}}}^{2}+\cos ^{2} \mathrm{zm}_{\mathrm{D}}^{2}+\mathrm{D}^{2} \sin ^{2} \mathrm{z} \frac{\mathrm{m}_{\mathrm{z}}^{2}}{\rho^{2}}}
$$

Again, we use the principle of equal influence of error sources. We get:

$$
\begin{gathered}
m_{D}=\frac{D}{\rho} m_{z}=m_{P}=m \\
\Delta H \geq z_{q} \sqrt{2} \sqrt{m^{2}\left(1+\cos ^{2} z+\sin ^{2} z\right)}=2 m z_{q} ;
\end{gathered}
$$




$$
\mathrm{m} \leq \frac{\Delta \mathrm{H}}{2 \mathrm{z}_{\mathrm{q}}}
$$

Finally, we get:

$$
\mathrm{m}_{\mathrm{z}} \leq \frac{\Delta \mathrm{H} \rho}{2 \mathrm{Dz}}=0,26 \Delta \mathrm{H} \frac{\rho}{\mathrm{D}}
$$

For example, for $\Delta \mathrm{H}=2 \mathrm{~mm}$ and $\mathrm{D}=50 \mathrm{~m}$, we get $\mathrm{m}_{\mathrm{z}} \leq 2,1^{\prime \prime}$.

\section{Conclusions}

Thus, we come to the conclusion that for observations of deformations of buildings and structures using the coordinate method, we need to use high-precision electronic total stations, which have an accuracy of measuring angles of no more than 2", and an accuracy of measuring distances of no more than $1 \mathrm{~mm}$.

To make observations, consider the question of electronic total stations that provide the values of deformations with the necessary accuracy.

The most recognizable brands on the market of electronic total stations are Sokkia, Topcon, Leica and Trimble. Table 3 shows the characteristics of the devices we are interested in and their cost:

Table 3. Values of standard errors of measurements of electronic total stations and their cost.

\begin{tabular}{|c|c|c|c|c|}
\hline Model & $\begin{array}{c}\text { Electronic total } \\
\text { station }\end{array}$ & $\mathbf{m}_{\boldsymbol{\beta}}, \mathbf{s e c}$. & $\mathbf{m}_{\mathbf{S}}, \mathbf{m m}$ & Cost, rubles. \\
\hline Sokkia & IX-1001 & 1 & 1 & 1839500 \\
\hline Topcon & GT-1001 & 1 & 1 & 1876250 \\
\hline & GT-1002 & 2 & 1 & 1771810 \\
\hline Leica & TS03 R500 & 2 & 1 & 726140 \\
\hline & TS07 R500 & 2 & 1 & 858020 \\
\hline & TS07 R1000 & 2 & 1 & 984020 \\
\hline & TS16 M R500 & 2 & 1 & 1386000 \\
\hline & TS16 M R1000 & 2 & 1 & 1503600 \\
\hline Trimble & S5 252110 & 2 & 1 & 1141430 \\
\hline & S5 252100 & 2 & 1 & 1317185 \\
\hline & S5 252210 & 2 & 1 & 1492399 \\
\hline & S7 253100 & 2 & 1 & 1492299 \\
\hline & S5 252200 & 2 & 1 & 1668050 \\
\hline
\end{tabular}

Analysis of table 3 shows that the cost of electronic total stations that provide measurements with the required accuracy is quite high. The price range varies, in practice, from 1 million rubles to 1.8 million rubles.

You can use total stations, which are about 2-3 times cheaper: the price range is about 500 thousand rubles to 700 thousand rubles. Accordingly, the accuracy characteristics of these devices, both when measuring angles and when measuring distances, are lower (table 4).

Table 4. Values of standard errors of measurements of electronic total stations and their cost.

\begin{tabular}{|c|c|c|c|c|}
\hline Model & $\begin{array}{c}\text { Electronic total } \\
\text { station }\end{array}$ & $\mathbf{m}_{\boldsymbol{\beta}}, \mathbf{s e c}$. & $\mathbf{m}_{\mathbf{S}}, \mathbf{m m}$ & Cost, rubles. \\
\hline Sokkia & IM-103 & 3 & 1.5 & 585650 \\
\hline Topcon & OS-103L & 3 & 2 & 680840 \\
\hline Leica & TS02plus R500 & 3 & 1.5 & 511749 \\
\hline Trimble & S5 352110 & 3 & 2 & 604140 \\
\hline
\end{tabular}


In this case, according to the theory of measurement errors, to obtain the displacement values with the necessary accuracy, it is necessary to perform two measurements. Then the average value of the horizontal and vertical offsets from the two techniques will be at the root of the two more accurate.

\section{References}

1. A.L. Voroshilov, Bulletin of the South Ural state University 13, 37-39 (2005)

2. Geodetic tools. Sokkia SET230RK non-reflective electronic total station: operating Instructions

3. B.N. Zhukov, A.P. Karpik, Geodetic control of engineering objects of industrial enterprises and civil complexes (Publishing house of SSGA, Novosibirsk, 2003)

4. A.K. Zaitsev, S.V. Marfenko, D.S. Mikhelev, Geodesic methods for studying deformations of structures (Nedra, Moscow, 1991)

5. V.N. Kalinin, S.D. Sokolov, A.N. Topilin, Inspection and testing of structures of buildings and structures: textbook (INFRA-M, Moscow, 2005)

6. E.B. Klyushin, M.I. Kiselev, D.S. Mikhelev, V.D. Feldman, Engineering geodesy (Akademiya, Moscow, 2008)

7. Benefit to Moscow city building codes 2.07.01 "Survey and monitoring during the construction and reconstruction of buildings and structures" (Moscomarchitecture, Moscow, 2004)

8. Guide to determining the inclines of tower-type engineering structures using geodesic methods (Stroizdat, Moscow, 1981)

9. Guidelines for monitoring deformations of foundations and foundations of buildings and structures (Stroizdat, Moscow, 1975)

10. N. Vatin, N. Lavrov, G. Loginov. MATEC Web of Conferences. 2016. 73. DOI:10.1051/matecconf/20167301006.

11. N. Vatin, A. Sinelnikov, M. Garifullin, D. Trubina. Applied Mechanics and Materials. 2014. 633-634. Pp. 1037-1041. DOI:10.4028/www.scientific.net/AMM.633-634.1037 